\title{
Beauty and the iPod - a story of contrasts and the use of podcasting in vocational education - Nail Technology
}

\author{
Catherine Naamani ${ }^{\mathrm{a} *}$ and Louise Taylor $^{\mathrm{b}}$ \\ ${ }^{a}$ Centre for Excellence in Learning and Teaching, University of Glamorgan, Pontypridd, UK; \\ ${ }^{b}$ Hairdressing and Beauty Therapy, Ebbw Vale Campus, Coleg Gwent, UK
}

(Received 9 March 2012; final version received 29 May 2012)

\begin{abstract}
This paper takes a case study approach to provide evidence of the benefits of podcasting as a tool used to support a vocational qualification in the subject area of Hairdressing and Beauty Therapy (Nail Technology). It reflects on the experiences of both the lecturer and the students and concludes that podcasting is a valuable tool, supporting a range of learner needs and abilities. The paper presents the journey made by one Further Education (FE) lecturer and her students as they discover that by using freely available resources, such as open source software and low cost, handheld technologies, they learn more effectively, are more engaged and are able to share what they have created with their peers, future cohorts of students and through platforms such as PodOmatic and iTunes, the world. The paper demonstrates that both the creation process and the final product (the podcast itself) are equally valuable in engaging the learners by supporting self- and peer-assessment and through providing timely feedback. The paper suggests areas for further research and evaluation of using this technology in vocational education.
\end{abstract}

Keywords: podcasting; enthusing Learners; vocational education; handheld devices; FE

\section{Introduction}

In the UK, adults are increasingly using mobile and handheld devices to access the Internet at times and places to suit them (Ofcom 2010). This growth in the use of mobile devices has prompted educationalists to explore how they can promote more flexible and relevant opportunities to enhance learning and teaching, with attention being given to the role of mobile learning as a way of promoting inclusivity and greater learner focus. Podcasting is one of the tools available to support this. Research into the use of podcasting in post-compulsory education tends to focus on examples in Higher Education with little evidence of podcasting being used in Further Education (FE) settings, particularly in vocational education. This paper presents a case study where podcasting is being used to support key components of a vocational qualification in the subject area of Hairdressing and Beauty Therapy (Nail Technology) and presents the journey made by one FE lecturer and her students as they discover that by using freely available resources, such as open source software and handheld technologies, they learn more effectively, are more engaged and are able to share what they have created not only with their peers, but also with

*Corresponding author. Email: cnaamani@glam.ac.uk 
future cohorts of students and, through freely available platforms such as PodOmatic and iTunes, potentially with the world.

\section{Context}

The students involved in the case study were studying a Level 2 Diploma in the vocational area of Nail Technology and were based at a further education college in the Heads of the Valleys area in South Wales (UK learners are expected to achieve Level 2 qualifications on school-leaving age, that is, when they reach age 16). The area faces particularly high levels of economic inactivity and low educational attainment, coupled with poor telecommunications links in some areas (Welsh Government 2006). In order to address this, the Welsh Government has funded an ambitious 15 year strategy to drive regeneration in the region, a key theme being the development of the Heads of the Valleys Education Programme, which aims to ensure that people living in the area have access to a wide range of relevant academic and vocational qualifications, which will encourage progression to higher education and promote lifelong learning (Welsh Government 2007). The development of Information and Communications Technology (ICT) skills is seen as core to improving people's employability and the effective use of technology in learning and teaching as a means of engaging young people in education, a key challenge given the poor infrastructure in the area.

\section{The literature}

Stephen Heppell (2010) challenges our concept of the traditional classroom where "content is king" and "knowledge is delivered" suggesting that in today's world, "knowledge is constructed, and deconstructed, in social networks and 180 degree relationships exchange wisdoms". He goes on to suggest that technology has had a major role to play in this transformation, reflecting on the point that:

... for our young post-Google generation email is unfashionably what your dad does, technology lives in a pocket, and life in an Office sounds like a sentence. (Heppell 2010)

Heppell's view is shared by Skiba and Barton (2006) and Duncan-Howell and Lee (2007), who suggest that students growing up in the last decades of the twentieth Century have had access to digital technologies in ways that previously were not possible. They are Prensky's renowned "digital natives" (Prensky 2001) who are forcing "educators [...] to grapple with what form and shape learning will look like in tertiary settings in the next few decades" (Duncan-Howell and Lee 2007, p. 223). A key component in this learning revolution is the growth of handheld technologies, which have the potential to have a great impact on learning by facilitating opportunities for mobile learning (m-learning), which has advantages over e-learning because it extends beyond the classroom, creating more flexible, personal and collaborative learning environments (Naismith et al. 2006; Evans 2008). Learning is taken to the learner and the boundaries between formal and informal learning become blurred (Campbell 2005; Duncan-Howell and Lee 2007).

Much of the research into the use of mobile technologies tends to focus on specific curriculum areas (Allen 2006; Frantangeli 2009, cited in Lauritzen 2010; Naismith et al. 2006) while Lauritzen (2010) indicates that research into the use of these technologies in vocational education has been non-existent. Likewise 


\section{Naamani and L. Taylor}

Duncan-Howell and Lee (2007) report that there has been limited research on projects on m-learning in further and higher education. Indeed, in the authors' experience, within further education especially, the emphasis is placed on e-learning and the use of Virtual Learning Environments (VLEs). The review of the relevant literature in this paper consequently focuses primarily on those authors reporting on the use of podcasting in a vocational education setting.

The term "podcasting" was first used by Ben Hammersley (2004), reporting on the increasing variety of relatively, cheap, easily accessible and portable tools designed for online publishing. The term was derived from Apple's trademark iPod. Today, podcasts can be played on almost any device that supports the MP3format. More recently, Frydenburg (2008, pp. 3-4) suggests that the term might more usefully be referred to as an acronym for "personal on-demand", a reflection of the immediacy of a medium "which allows individualized content to be 'broadcast' to one's [own] device simply by downloading it". This is further personalised where users choose to subscribe to an Really Simple Syndication (RSS) feed, which "pushes" subscribed content to the user through an aggregator such as iTunes rather than them have to manually search for updated content (Campbell 2005).

The benefits of podcasting for both learning and teaching are widely reported with many researchers (Chan and Lee 2005; Evans 2008; Hargis and Wilson 2005, cited in Dale 2007; Roschelle 2003) commenting on its flexibility, spontaneity and capacity to engage learners, a view reiterated by Covill and Gill (2008, p. 1) who describe podcasts as valuable teaching resources "which provide a flexible and engaging learning environment and help to accommodate a wider variety of learning styles". They go on to suggest that podcasting can also support a richer learning experience and more learner-centred opportunities for assessment and feedback. Such an approach supports Petty's (2007) concept of "active learning", where learning becomes more authentic and relevant to the needs of the learner.

The social aspect of podcasting is discussed by Dale (2007, p. 49) who contrasts the use of podcasting in a social context, where it has enabled users to become "amateur broadcasters from the comfort of their own homes" with its potential in an academic context where he suggests it can support innovative and creative opportunities for more flexible learning, catering for a wide range of learning styles and developing skills such as communication and critical thinking. Significantly, he remarks on the view that "From a user-creator perspective, Podcasting offers a degree of self-empowerment, control and autonomy" (Dale 2007, p. 50), reinforcing the role of the user, or in this case, the learner, in using podcasting in education. This view is shared by Baird and Fisher (2006) and Huann and Thong (2006, in Barry and Abt 2007), amongst others.

The benefits of using podcasting to support teaching are not universally agreed however, with some researchers commenting on the disbenefits and areas of concern. Dale (2007) counsels against using podcasting purely as an alternative to face-to-face contact, suggesting that their role is as an enhancement to other forms of learning and one which responds well to a student body with increasingly high expectations of technology. In a similar vein, Allen (2006), Becher-Young (2009, cited in Lauritzen 2010) and Frantangeli (2009, cited in Lauritzen 2010) express the fear amongst educators that increasing use of podcasting will have a negative impact on attendance and attainment, a view which contrasts with Deal (2007) and Evans (2008) who report that most students perceive podcasts as a tool for reviewing lectures, rather than as an opportunity to miss them altogether. Similarly, the findings of Janssen 
(2009, cited in Lauritzen 2010) and Brittain et al. (2006) suggest that the use of podcasting as a review and revision tool had a positive effect on exam results. Students report that "... podcasts [are] efficient, effective, engaging and easily received learning tools for revision" (Evans 2008, p. 497).

The challenge remains, however, in developing the use of mobile technologies and podcasting so as to "improve [...] pedagogical approaches to information processing and conceptual learning" (Hargis and Wilson 2005, cited in Dale, 2007, p. 51). Barry and Abt (2007), Deal (2007) and McLean and White (2009) remind us that successful podcasting is dependent on the aim of the activity taking place and that considerations must include the articulation of clear learning outcomes coupled with well defined expectations for the learner while Duncan-Howell and Lee (2007, p. 223) warn that:

the use of M-Learning tools themselves does not guarantee their potential being realised. The key to success is the ability of educators to design and develop pedagogically sound opportunities and environments that enhances learning.

Undoubtedly, from a teaching perspective, the use of podcasts to save time (Knight 2006), to provide revision material (Barry and Abt 2007) or to disseminate course material (Frydenburg 2008) can have a positive impact on the learner experience. However, in reflecting on the use of podcasting as a tool for learners, researchers suggest that handing over the creation of content to the students can have even greater impact. Atkinson (2006), Barry and Abt (2007) and Frydenburg (2008) all report of the positive impact of podcasting to support learning and see the role of the learner as key in the process. The suggestion is, where learners create their own podcasts, greater collaboration is promoted while the "social" aspect of podcasting encourages increased dialogue and sharing both of which support innovative approaches to assessment and feedback. The development of ICT skills is seen as a bonus.

\section{Method}

The aim of this research is to assess the benefits of podcasting as a tool used to support a vocational subject (Nail Technology) and to consider the impact that a change of approach in teaching method has had in a particular classroom setting. It was important to undertake the research with a relatively small cohort of students initially, to ensure that access to technology would not be a barrier, to facilitate group management and in view of the proportion of the programme identified for the study. The findings are analysed using a combination of methods - a case study of the experience of the student cohort supported by informal interviews, and an action research approach which evaluates the impact the introduction of podcasting has had in a particular education setting.

The FE lecturer was studying a Level 7 module, The Pedagogical Application of ICT in Learning and Teaching, which is designed to engage those working in schools and colleges with ICT as a tool to enhance learning, teaching and assessment. The focus of the module is on the use of the technologies and approaches made possible by the development of ubiquitous ICT in the classroom context. The module is especially relevant to the aims of the Heads of the Valleys Education Programme as it aims to improve both the ICT skills of the students and supports teachers and 


\section{Naamani and L. Taylor}

lecturers to explore the pedagogical underpinnings of using ICT to engage and enhance learning and teaching.

A core component of the module is the design of a learning activity using JISC's Effective Practice Planner (JISC 2004), which prompts teachers to place the learners at the centre of the learning design, thus supporting the research in this area. When considering the design of a learning activity incorporating modern technology to act as an easily accessible revision and catch up tool/resource that would support the learner and tutor, podcasting seemed to be quite an innovative approach that would suit the needs outlined. It also allowed the opportunity for both the learner and tutor to delve into the m-learning.

As we have indicated, the cohort that participated in the podcasting activity was working towards a Diploma in Nail Technology at Level 2, which is a vocationally related qualification (VRQ). The cohort comprised seven learners aged 18 and under, two in the middle age range at 21 and 23 years old and two more mature learners at age 27 and 31; 11 learners in total. All were female with English as their first language and computer literate. The group generally had a high level of motivation to achieve, although a few lower level learners appeared to lose interest in tasks very easily. Retention and attendance, historically, is a problem and motivation to undertake revision outside of the classroom can also be problematic. The students work well in group tasks and in student led activities and tend to enjoy hands on activities.

The learning objectives for the podcasting activity were for two groups within the cohort to prepare for, design and produce a podcast to demonstrate their understanding of knowledge delivered in Term one. The rational being, as Frydenburg (2008) indicates, that podcasting is an even more powerful tool when students are responsible for the content creation, conducted in this way. Utilising a blended learning approach, the podcast was embedded into the College Virtual Learning Environment (Moodle), as well as, an RSS feed from PodOmatic, the start of the bank of podcasting resources for staff and students in forthcoming academic years.

There were no special requirements for the activity as the resources were readily available onsite; the preparatory work for the podcast took place in a classroom environment and recording took place in a quieter area via a laptop with microphone (student mobile phones or any other audio recording device could be utilised) using Camtasia Studio software (Audacity could be utilised). This was also used for editing and production. Access to the Internet (IT suite/Wi-Fi) was needed in order to connect to the host PodOmatic and to link via RSS feed to the VLE.

As indicated by the research (Dale 2007), it is suggested that podcasting caters for a wide range of learning styles and preferences. A VARK (Visual, Auditory, Read/ Write, Kinaesthetic) questionnaire (Fleming 2011) is already adopted by the College to build up an understanding of a student's profile as part of the induction programme and to support differentiated learning. A review of the students' profiles determined that eight of the cohort showed a multimodal VARK preference, one a multimodal VAR with another an RK preference. One learner demonstrated a strong preference towards Read/Write (R/W).

Learners in the cohort were familiar with the differentiated groups they were assigned to for group work, arranged by their learning preference, attention span, characters and literacy assessment levels (the majority work at Level 1). The rationale being the Level 2 learners are additional support to the tutor and the Level 1 learners in their assigned groups. These predetermined differentiated groups were utilised 
for the podcasting activity. Using this approach, combined with the information gathered on learning preferences, Level 2 learners were assigned "Pod Captain" roles, in which they captained their group and reported to the tutor. Other set roles, that is, scribe, timekeeper and presenter, were negotiated and assigned by the group members.

Barry and Abt's Podcasting Model (2007) was adopted to develop the podcasts. This model poses a series of questions that the tutor should consider before embarking on using podcasting and the associated technology in their teaching and learning. These include the aim of the activity, key pedagogical considerations such as type of podcast, target audience and format, the impact of the podcasts on learning and any technical issues.

The students were able to access the completed podcasts both via PodOmatic and on the college VLE. This approach ensured that all students were able to access the resources and while Evans (2008) suggests that maximum benefit comes from downloading podcasts onto a portable device, it was important to make sure that students without portable devices were not prevented from accessing material.

\section{Outcomes}

Generally, the learners mixed and worked well in their assigned groups. The more extrovert learners tended to be the presenters, while the more introverted tended to be the scribe. The clearly defined objectives and roles, as Kirkwood and Price (2005, cited in Barry and Abt 2007) suggest, ensured learners were clear on what they were supposed to do, why they were expected to do it and how it would enhance their learning. The process and finished product allowed assessment of knowledge and student performance. Learning took place predominantly through the podcast creation and group work activity, but also through the finished podcasts. Essential Skills in Communication and ICT along with Key Skills in Working with others and Improving Own Learning Performance were developed. The activity also gave motivation for revision. The activity created a self-correcting classroom; the process and product allowed an opportunity for misconceptions to be detected and for learning errors and omissions to be diagnosed. The activity provided opportunities for correction with the learners checking for their own, and each other's mistakes and omissions through self- and peer-assessment. Peer discussion, tutor feedback and other "reality checks" assisted with alleviating learning errors and omissions.

This was a constructivist approach, which required the learners to develop constructs and form their own meaning or interpretation of the outlined material. It also made the learning and revision more fun, interesting and interactive. The activity adopted an active learning approach; multimodal that supports all learning preferences, blends well with the learning environment and suits the learners and meets their needs i.e. active learning, learning by doing. The activity was inclusive to all via allocated roles in groupings.

Group 1 produced an excellent podcast that was succinct, well presented, humorous and easy to listen to. Group 2, although they produced a very good podcast, eventually needed to edit and re-record in some areas due to incorrect knowledge divulged. It was not as succinct with little humorous effect and monotonous in comparison with the podcast created by Group 1. This produced the desired effect however, by creating a self-correcting classroom with the learners 


\section{Naamani and L. Taylor}

able to demonstrate autonomy via the measurement of correct knowledge on the podcast recording and through group work discussions. Measurement through competency in online tests, in the main programme area, is possible, as Brittain et al. (2006) found $85 \%$ of his survey respondents said podcasting had a positive effect on their exam grades. Whilst online test results can be cast as a measurement against the podcasting activity the author was not able to determine this at present due to time restrictions, but would be possible with future cohorts.

The activity, generally, was very successful. Two podcasts out of the three that were planned were developed and put onto the PodOmatic platform and college VLE. The learners really enjoyed assigning themselves the group roles and most excelled in these roles. Confidence and familiarity with the methods and tools played a big part in this first trial; confidence grew as the activity developed and tended to improve further with repetition of task. Difficulties were encountered, however, where the use of technologies such as PodOmatic were blocked by the college firewall, limiting the benefits of using this platform as a "push-pull" technology. Similarly the institution's policy of placing all resources onto the VLE meant that it wasn't possible to use technology such as iTunes.

\section{Feedback from the learners}

The voice of the presenter played a big role, as suggested by the learners; it needed to be exciting and easy to listen to. The presenter could be, in future, be decided between the tutor and the group and as Dale (2007) suggests, a "how to" guide and full induction into using podcasts would be beneficial. Humour of the presenter was described by the learners as an important feature.

I really enjoyed making the podcast ... it was funny listening back to our podcasts.

I think it is better when the presenter is funny too, makes it better to listen to not so boring. (student comment)

The length of the podcast should not be too long; Dale (2007) suggests 6-9 minutes to be a reasonable duration. In the authors' view, informed by learner feedback, it would be beneficial to reduce this further to 3-5 minutes. Again this could be outlined in the podcast guidelines. The impact of the finished product, that is, a catch-up tool could not be fully measured with this cohort. This could be gauged, with better perspective, with a new cohort of learners. One learner added.

I thought that the podcasting was good for revision ... I'm not sure how much I would listen again to the finished podcast we made. (student comment)

In the future, it would be beneficial to trail the use of handheld devices to record podcasts and download directly in class to mobile devices.

I'd probably listen to the podcast on my phone if I missed a lesson. (student comment)

\section{Reflections}

Obstacles to overcome include accessibility issues and that of the institution's firewall restrictions. The firewall restricted access to the podcast on PodOmatic when embedded on the VLE and accessed from within the institution. In spite of this limitation, it was felt to be an essential aspect of the study that learners should be able to access the podcasts on a handheld device such as a Smartphones. In the 
future, the feasibility of utilising Smartphones for students to record and upload on their own devices and deploy onto larger platform such as iTunes $U$ will be explored. Such an approach would be beneficial in providing a framework for sharing resources more widely in a cost-efficient way with other learners, practitioners and the extended.

\section{Conclusions}

While the group size was small, the findings of this study appear to confirm what we have read in the literature, namely that podcasting in education is a valuable tool, supporting peer-assessment and revision and providing immediate feedback to both learners and lecturers as to the level of understanding achieved. Similarly, as indicated by the research, the process of allowing the learners to create the podcast is as beneficial as the product itself; it promotes effective group work by building on the different strengths in a group and caters for different learning styles. Consequently, the activity becomes entirely learner-focused and learner-led. To ensure their success, however, podcasts need to be clearly structured and where students are creating the podcasts, aims need to be clear. In addition, while for this study the group's ICT skills were generally good, it is advisable to provide technical support for students on using the software and guidance on what constitutes a "good" podcast, for example, podcasts should be short and the presenting style should be up-beat and engaging. In this way, the activity supports the development of wider skills that go beyond ICT.

The indications are that this approach lends itself well to other vocational subject areas and by encouraging and supporting learners to bring and use their own devices, the approach becomes more easily scalable. It is, however, important to be aware of institutional policies in using particular hardware or software. As has been indicated, in the case of this study, the chosen platform for sharing the podcasts, PodOmatic, was in fact blocked by the college firewall and many of the benefits associated with podcasting, such as subscription to RSS feeds or publication to a wider audience, were lost because of the policy to place all resources within the college VLE. It is, therefore, important to involve IT support while planning your activity as while institutional policy might be viewed as inhibiting innovation and potentially accessibility, their early involvement may help overcome some of these barriers and ensure that learners are able to access the tools more easily.

\section{Future plans}

Future cohorts will now have podcasts available for review and those undertaking future podcast activities will now have a sample podcast to aspire to, to create or improve upon. Evaluation will focus on the extent to which these resources are used for learning and revision in combination with their impact on student attainment in the online tests which form part of the end-of-unit summative assessment criteria. It will also be important to consider the extent to which the success of the first cohort of students is a result of the novelty factor or is this an approach which continues to engage and motivate future cohorts. Other themes for further research will include providing opportunities for learners to use their own devices to create podcasts as well as to access them, therefore empowering the learner to an even greater extent; 


\section{Naamani and L. Taylor}

and given the encouraging feedback from this study, exploring the extent to which the use of podcasting can be expanded to include other vocational areas.

\section{References}

Allen, B. (2006) 'Podcasting in education an intellectual biography', [online] Available at: http://education.transbat.com/courses/eme6405/IntelBioFinalPaper.pdf

Atkinson, R. (2006) 'Podcasting: do you really need to know?' HERDSA News, vol. 28, no. 3, [online], Available at: http://www.roger-atkinson.id.au/pubs/herdsa-news/28-3.html

Baird, D. E. \& Fisher, M. (2006) 'Neomillennial user experience design strategies: utilizing social networking media to support "Always On" learning styles', Journal of Educational Technology Systems, vol. 34, no. 1, pp. 5-32.

Barry, T. \& Abt, G. (2007) 'A strategy for using podcasts for teaching and learning in the biosciences available through the centre for bioscience', [online] Available at: www. bioscience.heacademy.ac.uk/ftp/tdf/barrystrategy.pdf

Brittain, S., et al. (2006) 'Podcasting lectures', EDUCAUSE Quarterly, vol. 29, no. 3, 24-31, [online] Available from: http://www.educause.edu/EDUCAUSE+Quarterly/ EDUCAUSEQuarterlyMagazineVolum/PodcastingLectures/157413

Campbell, G. (2005) 'There's something in the air: podcasting in education', EDUCAUSE Review, vol. 6, [online] Available at: http://www.educause.edu/EDUCAUSE+Review/ EDUCAUSEReviewMagazineVolume40/TheresSomethingintheAirPodcast/158014

Chan, A. \& Lee, M. (2005) 'An MP3 a day keeps the worries away - exploring the use of podcasting to address preconceptions and alleviate pre-class anxiety amongst undergraduate information technology students', Student Experience Conference, Charles Stuart University, [online] Available at: http://citeseerx.ist.psu.edu/viewdoc/summary?doi=10.1.1. 115.1023

Covill, D. \& Gill, D. S. (2008) 'Using podcasts and videocasts to complement traditional teaching methods Social purpose and creativity - integrating learning in the real world', Articles from the Learning and Teaching Conference, University of Brighton, pp. 60-66, [online] Available at: http://eprints.brighton.ac.uk/7701/

Dale, C. (2007) 'Strategies for Using podcasting to support student learning', Journal of Hospitality, Leisure, Sport and Tourism Education, vol. 6, no. 1, pp. 49-57.

Deal, A. (2007) 'A Teaching with technology white paper; podcasting', [online] Available at: http://www.cmu.edu/teaching/resources/PublicationsArchives/StudiesWhitepapers/ Podcasting_Jun07.pdf

Duncan-Howell, J. \& Lee, K. T. (2007) 'M-learning: finding a place for mobile technologies within tertiary educational settings', Ascilite, Singapore 2007, Available at: http:// www.ascilite.org.au/conferences/singapore07/procs/duncan-howell.pdf

Evans, C. (2008) 'The effectiveness of m-learning in the form of podcast revision lecturers in higher education', Computers \& Education, vol. 50, no. 2, pp. 491-498.

Fleming, N. (2001). VARK a guide to learning styles, [online] Available at: http://www.varklearn.com/english/page.asp? $\mathrm{p}=$ faq

Frydenberg, M. (2008) 'Principles and pedagogy: the two PS of podcasting in the information technology classroom', Information Systems Education Journal, vol. 6, no. 6, pp. 1-11.

Hammersley, B. (2004) 'Audible revolution', The Guardian, [online] Available at: http:// www.guardian.co.uk/media/2004/feb/12/broadcasting.digitalmedia

Heppell, S. (2010) 'Learning, yearning and earning: why 21 st century learning is transforming schools, organisations and markets (keynote address)', Learning Technologies Conference, Olympia, London, [online] Available at: http://dp-x2.com/channels/learningtech/index. php?option $=$ com_datpresenter_archive\&expsec $=102$

Huann, T. Y. \& Thong, M. K. (2006) Audioblogging and Podcasting in Education, Ministry of Education Singapore, [online], Available at: http://scholar.google.co.uk/scholar?hl=en\&q= huann + thong\&as_sdt $=0 \% 2 \mathrm{C} 5 \&$ as_ylo $=\&$ as_vis $=0$

JISC. (2006) Effective Practice Planner, [online] Available at: http://www.jisc.ac.uk/media/ documents/programmes/elearningpedagogy/planner.doc

Knight, R. (2006) 'Podcast pedagogy divides opinion at US universities', Financial Times, [online], Available at: http://www.ft.com/cms/s/2/904272e4-9997-11da-a8c3-0000779e2340. html\#axzz1iEFeirc5 
Lauritzen, L. (2010) The use of video podcasts as a supplement to lecturers and demonstrations in a traditional hands-on vocational education laboratory environment, Unpublished Topic Paper for PhD Thesis, Northcentral University, [online], Available at: http://ncu. lauritzenfamily.net/LauritzenLRSH9101E-Activity_8-TopicPaper.pdf

McLean, D. \& White, E. R. (2009) 'Two approaches to podcasting use in the classroom', MERLOT Journal of Online Learning and Teaching, vol. 5, no. 2, pp. 336-347.

Naismith, L. et al. (2006) 'Mobile Technologies and Learning literature review', Futurelab, [online], Available at: http://www.futurelab.org.uk/resources/mobile-technologies-andlearning-literature-review

Ofcom. (2010) Facts \& Figures, [online] Available at: http://media.ofcom.org.uk/facts

Petty, G. (2004) Active Learning, [online], Available at: http://www.geoffpetty.com/activelearning. html

Prensky, M. (2001) 'Digital natives, digital immigrants part 1', On the Horizon, vol. 9, no. 5, pp. $1-6$.

Roschelle, J. (2003) 'Keynote paper: unlocking the learning value of wireless mobile devices', Journal of Computer Assisted Learning, vol. 19, no. 3, pp. 260-272.

Skiba, D. \& Barton, A. (2006) 'Adapting your teaching to accommodate the net generation of learners', The Online Journal of Issues in Nursing, vol. 11, no. 2, Manuscript 4.

Welsh Government. (2006) Turning Heads: A Strategy for the Heads of the Valleys 2020, [online], Available at: http://wales.gov.uk/deet/publications/bande/hotv/turningheads/ turningheadse.pdf?lang $=\mathrm{en}$

Welsh Government. (2007) Heads of the Valleys Programme, [online], Available at: http:// wales.gov.uk/topics/businessandeconomy/regeneration/strategicareas/HofV/?lang=en 